\title{
Big Data - vom Hype zur Anwendung
}

Die Größe eines Wortes stellt die relative Häufigkeit in den Beiträgen des Heft-Schwerpunktes dar.

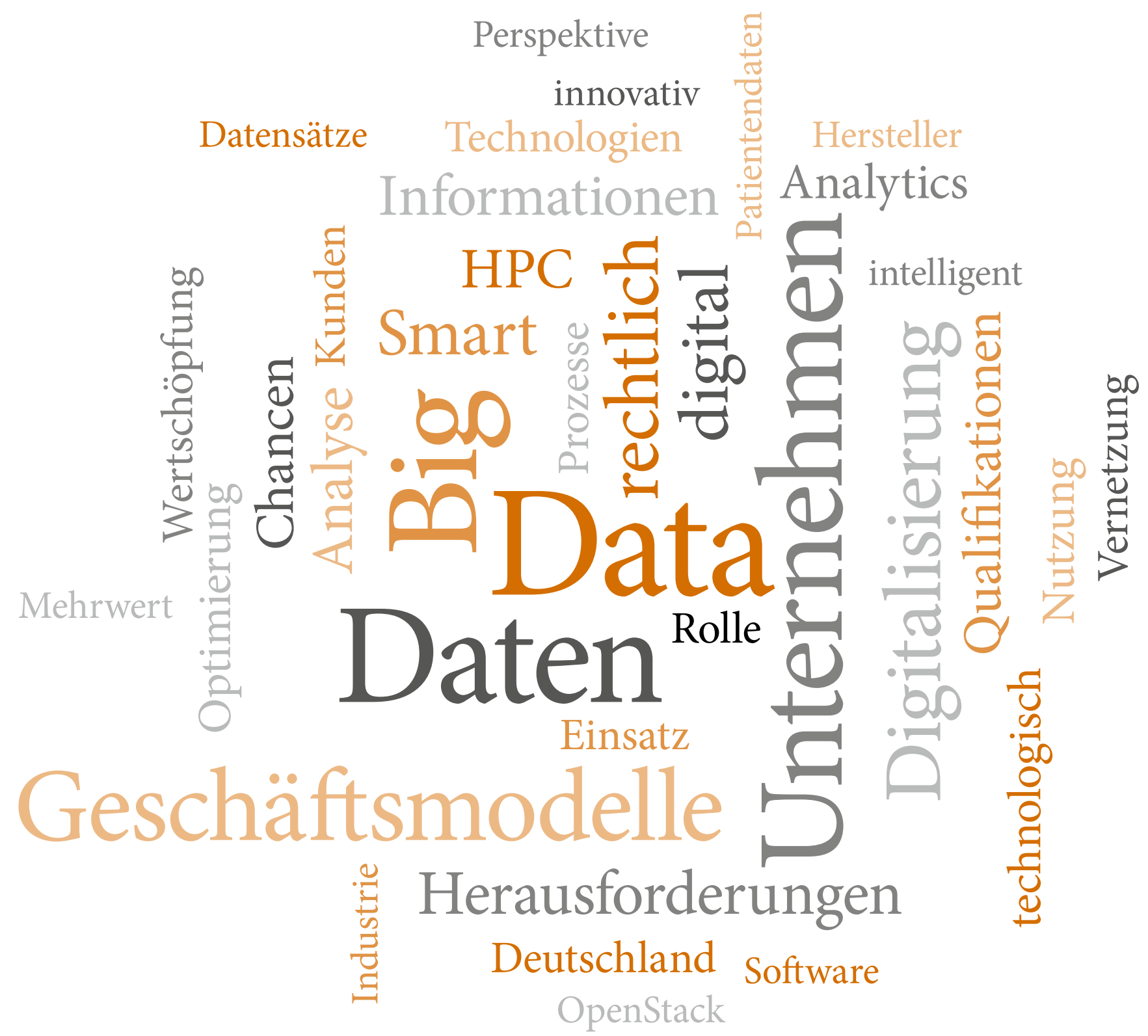

